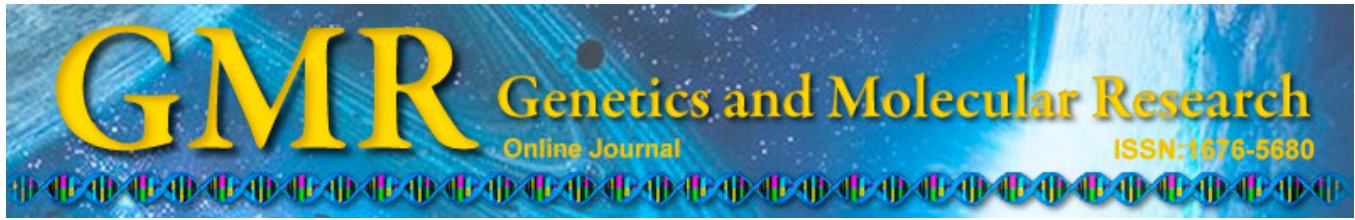

\title{
A new method to induce myasthenia gravis models and the protective effect of soluble decay accelerating factors
}

\author{
L. Sun ${ }^{1,2}$, L. Xing ${ }^{3}$, G.H. Zhang ${ }^{2}$ and S.Y. Pan $^{1}$ \\ ${ }^{1}$ Department of Neurology, Nanfang Hospital, Southern Medical University, \\ Guangzhou, China \\ ${ }^{2}$ Department of Neurology, \\ The Affiliated Hospital of Inner Mongolia Medical University, Hohhot, China \\ ${ }^{3}$ Department of Neurology, The China Ordnance Northern Heavy Group \\ Hospital (The Third Affiliated Hospital of Baotou Medical College), Baotou, \\ China
}

Corresponding author: S.Y. Pan

E-mail: pansuyuedn@126.com

Genet. Mol. Res. 14 (3): 7782-7792 (2015)

Received October 31, 2014

Accepted March 12, 2015

Published July 14, 2015

DOI http://dx.doi.org/10.4238/2015.July.14.4

\begin{abstract}
It is expensive to induce experimental autoimmune myasthenia gravis (EAMG) by active immunity, and difficult to obtain natural acetylcholine receptor (AChR). We sought a new method of inducing EAMG by immunizing rats with artificially synthesized AChR. The AChR mRNA in TE671 cells was extracted and reverse transcribed. The inclusion body was purified and protein concentration was determined, and the EAMG animal model was used for induction. The serum was extracted from rat blood. The antibody titer was determined using enzyme-linked immunosorbant assay (ELISA). The concentration of decay accelerating factor (DAF) in the rat serum was determined by ELISA, and the metabolism of serum rDAF was determined by western blot. We evaluated the inhibition of rDAF by determining the $50 \%$
\end{abstract}


complement hemolysis unit in the rat serum. The extracellular domain (ECD) nucleotide sequence clone produced by polymerase chain reaction was completely consistent with that in the human gene bank; it was induced by isopropyl $\beta$-D-1-thiogalactopyranoside to express the protein after insertion into vector pET16b. Sodium dodecyl sulfate polyacrylamide gel electrophoresis demonstrated that the inclusion body protein was the exact target. The ECD protein was able to bind with $\mathrm{mAb} 35$ after dialysis and renaturation, which demonstrated protein activity. The soluble ECD protein was used to immunize rats and obtain the EAMG models. The inhibitory effect of the complement was unsatisfactory owing to high decay rate after $\mathrm{rDAF}$ injection into the EAMG models. It is easy to induce the EAMG model by obtaining the AChRTE $\alpha 1$ subunit ECD protein using the substitution method.

Key words: Myasthenia gravis; Cholinergic receptor; Experimental autoimmune myasthenia gravis; Rat soluble decay accelerating factors

\section{INTRODUCTION}

Myasthenia gravis (MG) is an autoimmune neuromuscular transmission disorder and is characterized by loss of acetylcholine receptor ( $\mathrm{AChR}$ ) functionality arising from the action of anti-AChR antibody (Ab) (Conti-Fine et al., 2006; Willcox et al., 2008). At present, there are three explanations for its action mechanism (Lin et al., 2002; Gilhus et al., 2011; Pasutharnchat et al., 2012): (I) AChR Ab binds with adjacent AChR, thereby allowing endocytosis of recipient cells and leading to a decrease in the amount of $\mathrm{AChR}$ in the postsynaptic membrane; (II) autoantibodies directly interfere with AChR function by blocking the AChR binding site; and (III) autoantibodies are only catalysts for the loss of endplate AChR and involvement of the complement activation system is critical to MG pathology. Animals receive exogenous $\mathrm{AChR}$; the in vivo $\mathrm{T}$ cell immunologic response and $\mathrm{AChR}$ interact and generate autoantibodies, thereby inducing MG with symptoms similar to those of human MG. It is therefore possible to study MG by active immunization of experimental autoimmune myasthenia gravis (EAMG). However, it is difficult and expensive to acquire the electric ray (Torpedo californica) used, and many expensive reagents are required during extraction, such as $\alpha$-coral snake venom, making it more difficult to prepare EAMG. It is also relatively hard to obtain human muscle. The AChR in muscle degrades once separated and the amount extracted is small. Therefore, a convenient and fast method is required to induce EAMG. It is difficult to obtain natural AChR, so we considered immunizing animals with artificially synthesized AChR (Nastuk et al., 1959; Patrick and Lindstrom, 1973; Sathasivam, 2008).

Research has shown that the autoantibody for AChR plays a decisive role in MG incidence (Amsbaugh et al., 1972; Li et al., 2009; Wei et al., 2014) and is mainly specific to the $\mathrm{AChR} \alpha$ subunit $\mathrm{N}$ terminal extracellular domain (ECD) ( $\alpha 1-210)$. The ECD has a major immunogenic region (MIR), specific T and B cell epitopes, and AChR binding sites. The generated autoantibodies bind with the AChR binding sites on the ECD, thereby allowing deactivation of AChR, stimulating proliferation of specific T cells, activating the complement system, and leading to MG. We considered inducing animals using a fragment during preparation of the 
EAMG model. Research has shown that AChRTE (AChR from the TE671 cells of human nerve medulloblastoma) can also react with the human muscular AChR (AChRMU) monoclonal Ab (mAbs) (Gunewardene et al., 2012; Hunt, 2014; Kalel et al., 2014), including mAbs specific to the AChR ECD and MIR regions. It is possible to express AChRMU $\alpha$ subunit ECD protein using AChRTE recombination. In this experiment, a series of techniques, such as reverse transcription polymerase chain reaction (RT-PCR), vector construction, conversion, expression of proteins in Escherichia coli, and liquid chromatography, were successfully used to obtain highly purified ECD protein; and Lewis rats were immunized to prepare EAMG. The extracted and purified soluble rat decay accelerating factor (rDAF) was intravenously injected into the EAMG model for evaluation of its metabolism in serum and to study its role in MG protection.

\section{MATERIAL AND METHODS}

\section{Important materials and instruments}

Twelve female Lewis rats (HFK Bioscience Co., Ltd, Beijing, China), aged 8 weeks and weighing $159 \pm 9.8 \mathrm{~g}$ were used. We used bacterial strains BL21 (DE3) pLysS (Molecular Cloning Labs, Inc., Boston, MA, USA) and JM109 (Biovector Science Lab, Inc., Los Angeles, CA, USA). The plasmid was pET-16b (EMD Biosciences, Novagen, Los Angeles, CA, USA). High-fidelity TaqDNA polymerase, restriction endonuclease, T4DNA ligase, DNA marker, and the protein marker (TaKaRa Company, Tokyo, Japan).

A Sorvall tabletop centrifuge and a Sorvall tabletop low-temperature centrifuge were supplied by the Fresco Company, UK; the Avanti JE high-speed refrigerated centrifuge was from the Beckman Company, USA; the PTC-200 gradient polymerase chain reaction amplifier was from the MJ Research Company, USA; and the DYY-III electrophoresis apparatus was from the Beijing Liuyi Instrument Factory.

\section{Expression of the human recombinant ECD protein}

TE671 cell AChR mRNA was extracted and reverse-transcribed. The primers for the target fragments were designed using the Primer Premier \& Oligo software. Based on the $\alpha 1$ subunit full-length sequence, the primers were designed as follows: hAChRAu: 5' GTCCACACAAGCTCCGGTAG3', hAChRAd: 5' GTTCCAGGGCAGAGCTAAGC3', based on the structural gene of ECD, the primers were designed as follows: 16bup: 5'GCG CAT ATG TCC GAA CAT GAG ACC CGT CT3'; 16bdown: 5' AT CGG ATC CTC CAG GCG CAT GAC GAA GT3'; $N d e \mathrm{I}$ and $\mathrm{BamHI}$ enzyme digestion sites are underlined; the basic group mutation containing $\mathrm{G} \rightarrow \mathrm{A}$ is shown in bold.

The recombinant human AchR $\alpha 1$ subunit full-length sequence plasmid served as the template. The fragment to be cloned was amplified with high fidelity DNA polymerase (Pyrobest, TaKaRa Company, Japan). The PCR system is presented in Table 1.

Agarose gel electrophoresis analysis was conducted after the PCR was complete. The DNA was extracted using the ethanol precipitation method and the target fragments were collected. The vector ( $1 / 5$ volume) was added to the fragments collected, and T4 DNA ligase was added. The reaction tube was placed in a water bath at $16^{\circ} \mathrm{C}$ for $16 \mathrm{~h}$. Reagents were added for joining of the vectors and fragments. The joined vectors were converted. Five positive converters were selected at random and placed in a $2 \mathrm{X}$ YT medium containing $100 \mathrm{mg} / \mathrm{L} \mathrm{Amp}+$ at $37^{\circ} \mathrm{C}$, 
shaken at 240 revolutions per minute (rpm) for $12 \mathrm{~h}$, and digested with BamHI and NdeI. They were then subjected to electrophoresis for testing for the presence or absence of target fragments. The supernatant and sediment (inclusion body components) and the samples such as microprotein before and after induction were subjected to sodium dodecyl sulfate polyacrylamide gel electrophoresis (SDS-PAGE) analysis to investigate the expression of the target proteins.

\begin{tabular}{lc}
\multicolumn{1}{l}{ Table 1. Polymerase chain reaction (PCR) system. } \\
\hline Reagent & Volume \\
\hline 10X LA PCR buffer II $\left(\right.$ plus $\mathrm{Mg}^{2+}$ ) & $5.0 \mu \mathrm{L}$ \\
4dNTP mixture & $8.0 \mu \mathrm{L}$ \\
16 bup & $2.5 \mu \mathrm{L}$ \\
LA Taq polymerase & $0.5 \mu \mathrm{L}$ \\
AChR $\alpha 1$ subunit template & $5.0 \mu \mathrm{L}$ \\
dH $\mathrm{O}$ & $29.5 \mu \mathrm{L}$ \\
Total volume & $50.0 \mu \mathrm{L}$ \\
\hline
\end{tabular}

\section{Expression of protein purification and renaturation}

The inclusion body was purified first. The protein concentration was determined using the Bradford method (Peterson, 1983). The concentration of the inclusion body was $1.4 \mathrm{mg} /$ $\mathrm{mL}$ after purification. The protein was renatured by dialysis and the passivated protein was dissolved in the renaturation solution ( $8 \mathrm{M}$ urea, $20 \mathrm{mM}$ Tris) to produce a protein concentration of $500 \mu \mathrm{L} / \mathrm{mL}$. The diluted protein was placed in a dialysis bag and dialyzed according to the following regimen: $4 \mathrm{M}$ urea for $12 \mathrm{~h} ; 2 \mathrm{M}$ urea and cysteine saturate for $4 \mathrm{~h}$; and 20 $\mathrm{mM}$ Tris and cysteine buffer solution for $4 \mathrm{~h}$. The protein concentration was $450 \mu \mathrm{L} / \mathrm{mL}$ after renaturation. The renatured protein was used to make denatured and non-denatured samples for SDS-PAGE.

\section{EAMG animal model induction}

The 12 experimental Lewis rats (Beijing HFK Bioscience Co., Ltd.) were randomly assigned to four groups comprising three rats each: the control group, and experimental groups 1,2 , and 3. The control group was immunized with normal saline. Experimental groups 1, 2, and 3 were injected with the antigen at doses of 50,200, and $400 \mu \mathrm{g}$, respectively. They were immunized subcutaneously in the back. The serum was then extracted from the blood and the $\mathrm{Ab}$ titer was determined indirectly by enzyme-linked immunosorbent assay (ELISA).

\section{Investigation of the metabolism and functions of rDAF in rats}

rDAF $(2.1 \mathrm{mg} / \mathrm{mL})$ was intravenously injected into the EAMG rats through the foot dorsum for less than $1 \mathrm{~min}$. Blood samples $(0.3 \mathrm{~mL})$ were extracted after 5, 25, 45, 65, 90 , $105,125,145,245,365,485,605,725,845$, and $965 \mathrm{~min}$. The blood was drawn from the post venous plexus of the inner canthus of the rat. The blood samples were stored at $0^{\circ} \mathrm{C}$ for at least $4 \mathrm{~h}$ and centrifuged at $8000 \mathrm{rpm}$ for $5 \mathrm{~min}$. The serum was stored at $-20^{\circ} \mathrm{C}$. The concentration of DAF in the rat serum was determined by ELISA. The metabolism of serum rDAF was determined by western blot. A test was conducted to determine the level of rDAF that inhibited the rat serum complement [determination of the $50 \%$ complement hemolysis unit (CH50)]. 


\section{Statistical methods}

All data are reported as means \pm standard error of the mean. The data obtained were subjected to statistical analysis using one-way analysis of variance, followed by the Dunnett posttest for comparison between control and test groups using the SPSS 12.0 software (SPSS Inc., Chicago, IL, USA). A P-value of $<0.05$ was considered to be significant. For quantification of the reverse transcription polymerase chain reaction and western blot results, the gray scale of the pictures was quantified using a Gel-Pro Analyzer (Media Cybernetics, Inc., Annapolis, MD, USA). The fold changes of the mRNA and protein level are expressed relative to the readings of the control group.

\section{RESULTS}

\section{Expression of the human recombinant ECD protein}

Figure $1 \mathrm{~A}$ is a diagram of the $\mathrm{pET} 16 \mathrm{~b}-\alpha 1 \mathrm{ECD}$ plasmid structure. The $\alpha 1$ subunit fragment sequence is shown in Figure 1B. The size of the fragment on the second lane was 1433 bp. Sequencing demonstrated that no point mutation or frameshift mutation was present in the $\alpha 1$ subunit full-length sequence. The ECD fragment was joined with the plasmid; the size of the fragment on the second lane was $650 \mathrm{bp}$, and the size of the fragment digested on the third lane was $650 \mathrm{bp}$, as shown in Figure 1C. Sequencing demonstrated that the ECD clone was correctly and successfully inserted into the pET16b vector. Figure 1D presents the results of the SDSPAGE analysis of the target protein's expression. The relative molecular weight of the recombinant protein $(\mathrm{Mr})$ was $26.65 \mathrm{kDa}$ based on the BioEdit software calculation. Figure 1D shows that there is a new band at approximately $26 \mathrm{kDa}$. The protein size is consistent with the ECD protein. The target protein on the seventh lane was eluted after passing through the $\mathrm{Ni}^{2+}$ column.

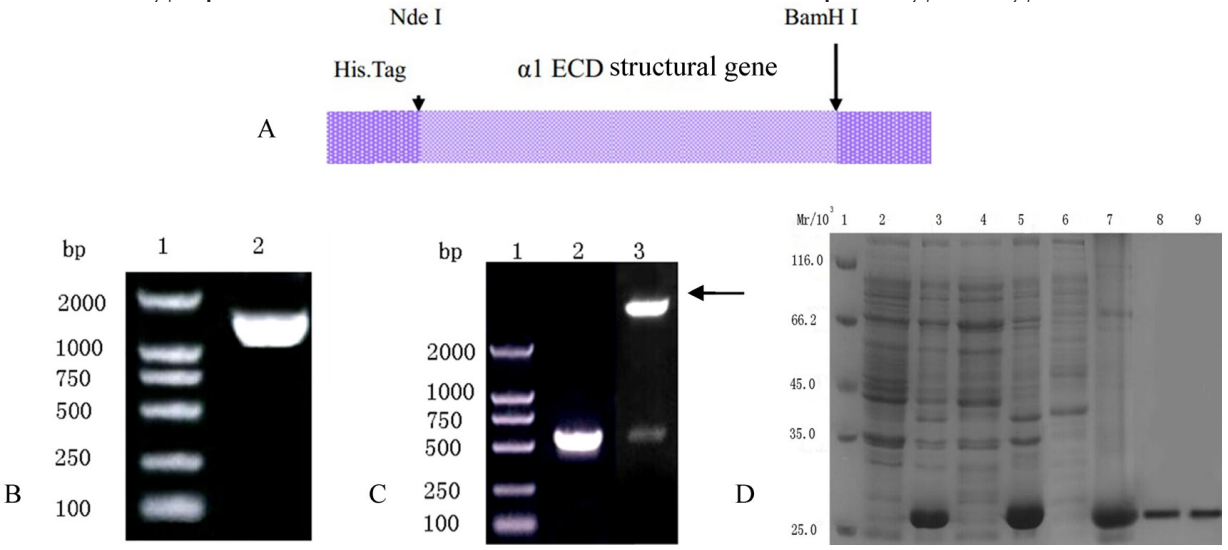

Figure 1. A. Recombinant plasmid structure chart. B. $\alpha 1$ subunit fragment; lane $1=$ marker and lane $2=$ target fragment. C. Extracellular domain (ECD) fragment joined with the plasmid; lane $1=$ marker, lane 2 = target fragment, and lane 3 = sample after enzyme digestion; the arrow indicates the vector. D. Results of sodium dodecyl sulfate polyacrylamide gel electrophoresis (SDS-PAGE) analysis of the target protein expression; lane $1=$ marker, lane 2 = microprotein before addition of isopropyl $\beta$-D-1-thiogalactopyranoside (IPTG), lane 3 = microprotein after addition of IPTG, lane $4=$ supernatant of the centrifuged lysis solution, lane $5=$ inclusion body of the centrifuged lysis solution, lane $6=$ penetration solution, lane $7=$ target protein after passing through the column, lane $8=$ renatured target protein, and lane $9=$ renatured target protein after addition of the reductive agent. 


\section{Expression of protein purification and renaturation}

The electrophoresis analysis results for the purified protein are shown in Figure 2A. All the target proteins were bound to the $\mathrm{Ni}^{2+}$ affinity column. Most of the miscellaneous proteins passed through the column. All the target proteins could be eluted with $0.8 \mathrm{M}$ imidazole. There were protein bands on the 8th and 9th lanes with Mrs of $26 \mathrm{kDa}$, indicating that the protein did not exist as an interpolymer. The optimum conditions for renaturation were: target protein, $5 \mu \mathrm{g} / \mathrm{mL}$; and $\mathrm{mAb} 35,0.5 \mu \mathrm{g} / \mathrm{mL}$. Figure $2 \mathrm{~B}$ shows that the protein sample bound with the mAb35 specificity, indicating that the protein was correctly folded after renaturation. The protein concentration was determined by the Bradford method. A standard curve was plotted based on the bovine serum albumin standard protein concentration (Figure 2C). The purified protein concentration was approximately $1.75 \mu \mathrm{g} / \mathrm{mL}$.

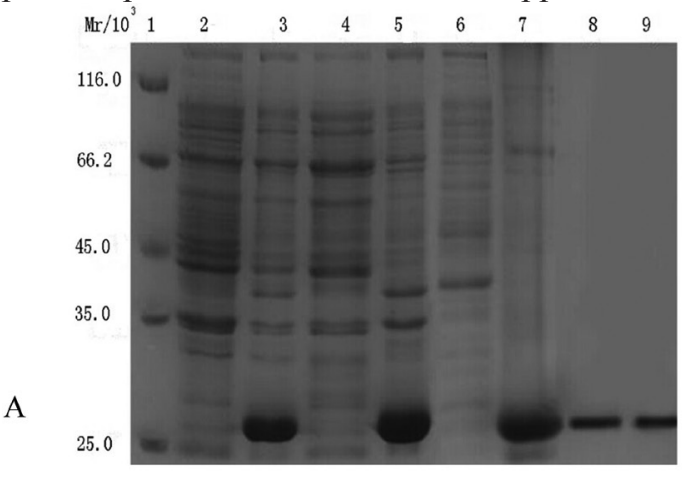

B
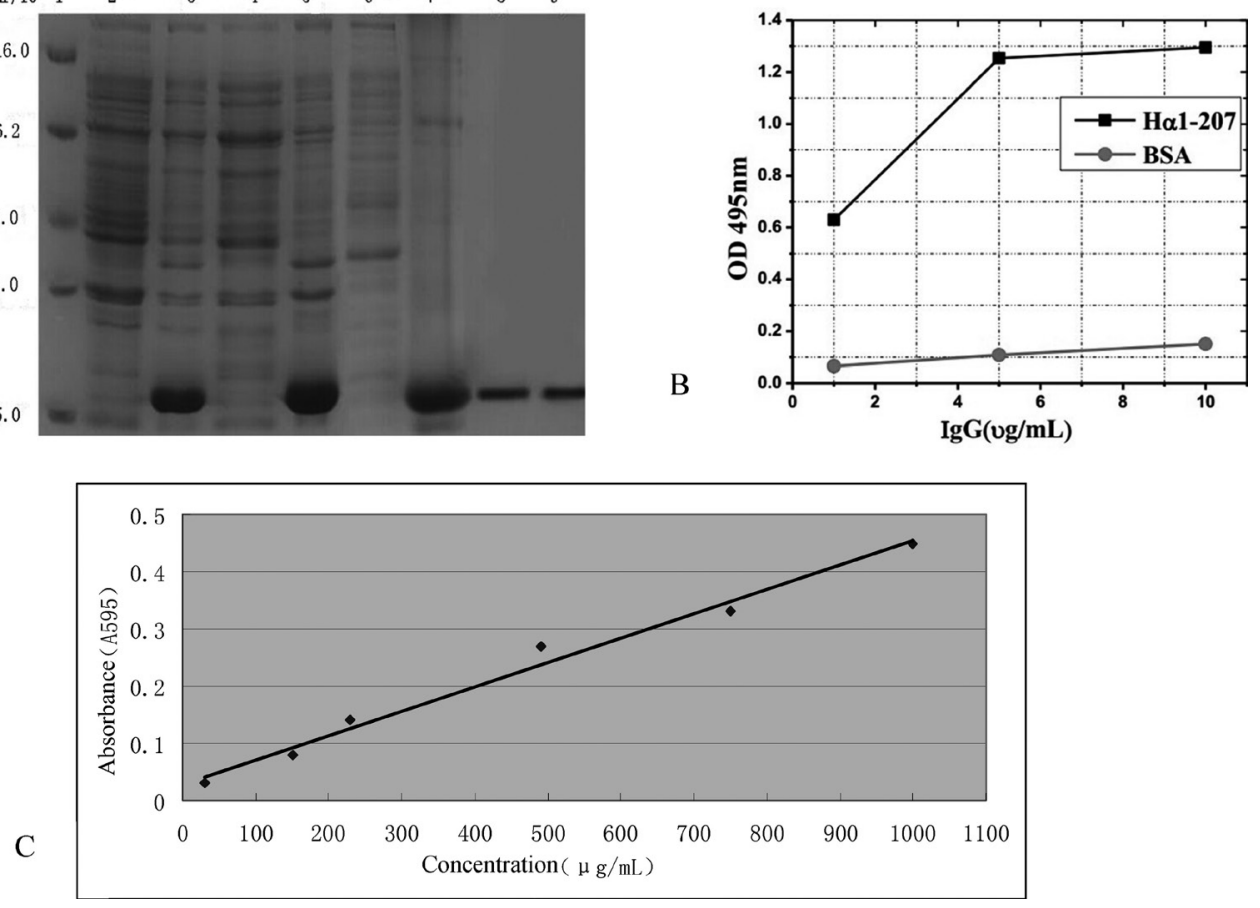

Figure 2. A. Results of the sodium dodecyl sulfate polyacrylamide gel electrophoresis (SDS-PAGE) analysis for the recombinant protein purification; lane 1 = protein marker, lane 2 = inclusion body dissolution solution, lane 3 $=$ penetration solution, and lanes 4-9 =0.8 M imidazole eluent. B. Results of the enzyme-linked immunosorbent assay (ELISA) investigation of the ability of the renatured $\mathrm{H \alpha 1-207}$ to bind with mAb35; the protein sample bound with $\mathrm{mAb} 35$ specifically (BSA = bovine serum albumin). C. Protein quantitative standard curve. The concentration of the purified protein was approximately $1.75 \mu \mathrm{g} / \mathrm{mL}$

\section{EAMG animal model induction}

No abnormal changes were observed in the rats during primary immunization. The 
coat luster of the experimental groups decreased slightly at 1 week after secondary immunization. In particular, rats in the 400- $\mu \mathrm{g}$ group moved less frequently and more slowly; they exhibited extreme fatigue after a very short period of time. These rats were rated as Grade I. The rats in the 200- $\mu \mathrm{g}$ group were rated as Grade 0.5 , and those in the $50 \mu \mathrm{g}$ group and the control group moved normally. The symptoms of the animals in the various groups were exacerbated after inoculation.

\section{Investigation of the metabolism and functions of rDAF in rats}

The concentration of DAF in blood 45 min after protein injection decreased to approximately $1 / 10$ of that 5 min after protein injection. It was difficult to determine DAF in the serum sample, indicating that the DAF was metabolized quickly (Figure 3 and Table 2).

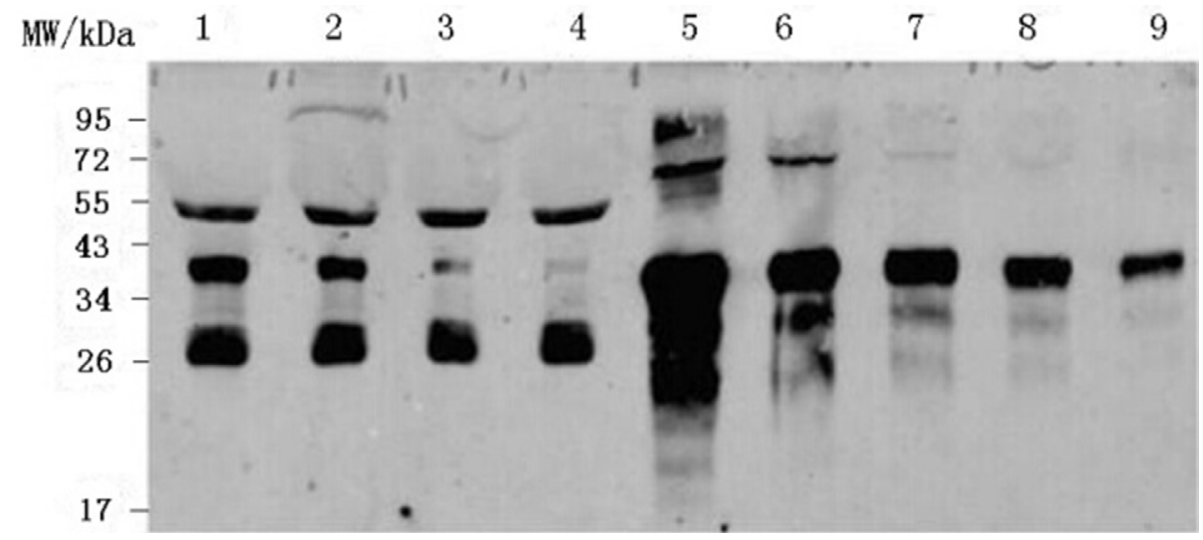

Figure 3. Examination of the rat serum samples using western blot. Lanes $1-4=$ serum samples at 5, 25, 45, and 65 min, respectively; lanes 5-9= standard.

Table 2. Determining the concentration of rat decay accelerating factor in serum using enzyme-linked immunosorbant assay (unit: $\mathrm{ng} / \mathrm{mL}$ ).

\begin{tabular}{|c|c|c|c|c|c|c|c|c|c|c|c|c|}
\hline & $\mathrm{A}_{495}$ & Pro $\mathrm{C}$ & True C & $\mathrm{A}_{495}$ & Pro C & True C & $\mathrm{A}_{495}$ & Pro $\mathrm{C}$ & True C & $\mathrm{A}_{495}$ & Pro $\mathrm{C}$ & True C \\
\hline & & $5 \mathrm{~min}$ & & & $25 \mathrm{~min}$ & & & $45 \mathrm{~min}$ & & & $1 \mathrm{~h} 5 \mathrm{~min}$ & \\
\hline $1: 10$ & $\mathrm{x}$ & $\mathrm{x}$ & $\mathrm{x}$ & 0.95 & $\mathrm{x}$ & $\mathrm{x}$ & 0.4 & 226 & 2,260 & 0.25 & 113 & 1,130 \\
\hline $1: 100$ & $\mathrm{x}$ & $\mathrm{x}$ & $\mathrm{x}$ & 0.65 & 449 & 44,900 & 0.19 & 67 & 6,700 & 0.13 & 27 & 2,700 \\
\hline $1: 1000$ & 0.43 & 247 & 24,700 & 0.28 & 132 & 13,200 & 0.15 & 44 & 44,000 & 0.15 & 40 & 40,000 \\
\hline \multirow[t]{3}{*}{$1: 5000$} & 0.17 & 54 & 27,000 & 0.17 & 54 & 27,000 & 0.15 & 44 & 440,000 & 0.13 & 32 & 160,000 \\
\hline & & $1 \mathrm{~h} 30 \mathrm{~min}$ & & & $1 \mathrm{~h} 45 \mathrm{mir}$ & & & $2 \mathrm{~h} 5 \mathrm{~min}$ & & & $2 \mathrm{~h} 25 \mathrm{~min}$ & \\
\hline & $\mathrm{A}_{495}$ & Pro $\mathrm{C}$ & Actual C & $\mathrm{A}_{495}$ & Pro C & Actual C & $\mathrm{A}_{495}$ & Pro C & Actual C & $\mathrm{A}_{495}$ & Pro C & Actual C \\
\hline $1: 10$ & 0.19 & 72 & 720 & 0.18 & 64 & 640 & 0.16 & 48 & 480 & 0.13 & 32 & 320 \\
\hline $1: 100$ & 0.12 & 22 & 2,200 & 0.12 & 24 & 2,400 & 0.12 & 21 & 2,100 & 0.11 & 16 & 1,600 \\
\hline $1: 1000$ & 0.14 & 38 & 38,000 & 0.15 & 44 & 44,000 & 0.14 & 38 & 38,000 & 0.16 & 48 & 48,000 \\
\hline $1: 5000$ & 0.14 & 38 & 190,000 & 0.15 & 44 & 220,000 & 0.14 & 38 & 190,000 & 0.15 & 44 & 220,000 \\
\hline
\end{tabular}

Pro $\mathrm{C}=$ protein concentration determined; Actual $\mathrm{C}=$ protein concentration determined $\mathrm{x}$ dilution ratio.

The result had a very good degree of fit with the ELISA method $(\mathrm{R}=0.998)$. The serum sample had a larger dilution ratio if it was taken at a later time, and the error caused was greater (Table 3 ). The actual test results were less than satisfactory. We accurately evaluated the rDAF level by western blot. 
Table 3. Rat decay accelerating factor (rDAF) quantitative curve formula.

\begin{tabular}{lrrr}
\hline & \multicolumn{3}{c}{ Blood sampling time (min) } \\
\cline { 2 - 4 } & \multicolumn{1}{c}{5} & 25 & 45 \\
\hline Total gray value of the rDAF band & 33.96 & 16.69 & 1.19 \\
Actual sample loading quantity of serum $(\mu \mathrm{L})$ & 0.83 & 0.83 & 0.83 \\
Protein quantity corresponding to the rDAF band $(\mu \mathrm{g})$ & 0.45 & 0.27 & 0.04 \\
Concentration of rDAF in serum $(\mathrm{mg} / \mathrm{mL})$ & 0.54 & 0.32 & 0.83 \\
\hline
\end{tabular}

$\mathrm{CH} 50$ is one of the most sensitive indices for reflecting the complement activation degree. In the experiment, it was found that there were no statistically significant changes in the CH50 value before and after the injection of rDAF (Figure 4). rDAF did not inhibit the complement.
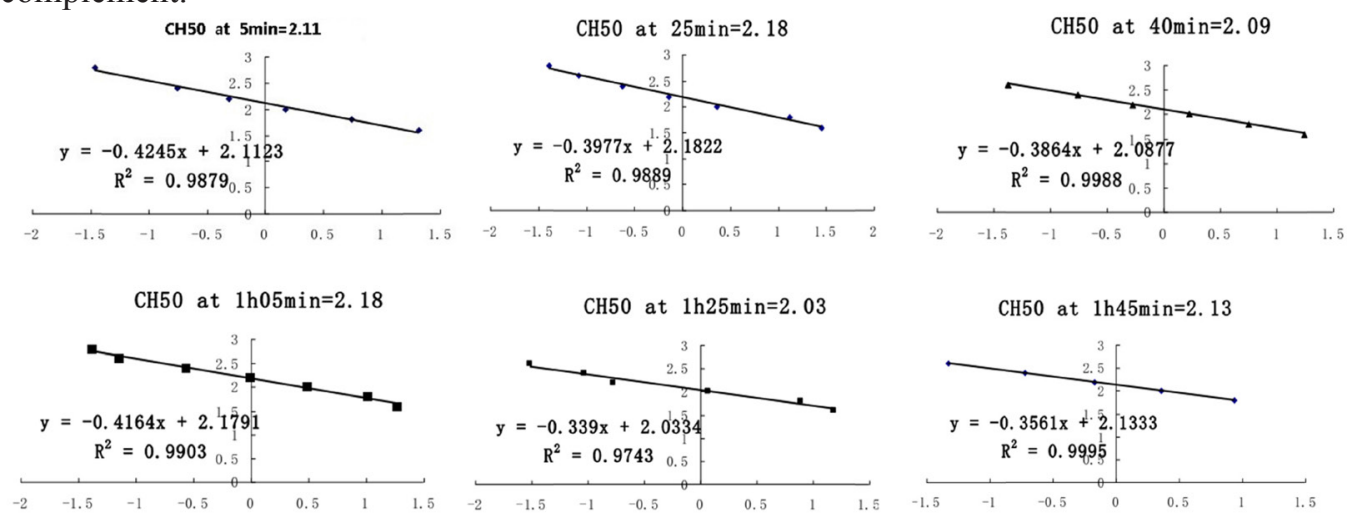

$\mathrm{CH} 50$ at $2 \mathrm{~h} 05 \mathrm{~min}=2.09$

$\mathrm{CH} 50$ at $2 \mathrm{~h} 25 \mathrm{~min}=2.14$
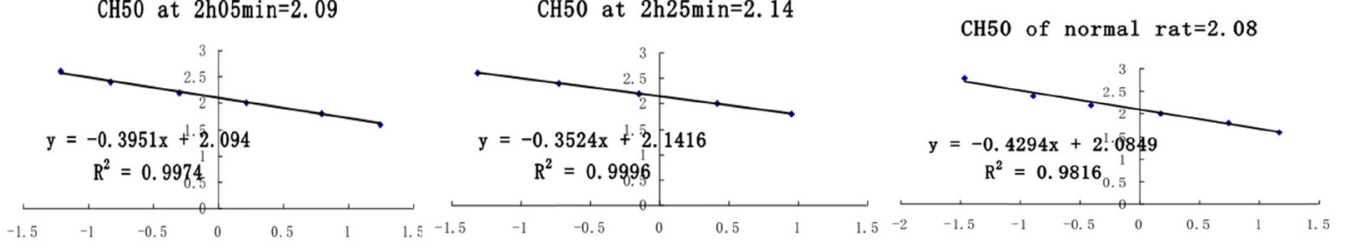

Figure 4. Calculation of $\mathrm{CH} 50$ at different points in time after intravenous injection of rat decay accelerating factor (rDAF) into rats. rDAF inhibited complement activation in the in vitro test but not in the in vivo test. There was a high concentration of rDAF in the serum sample taken 5 min after rDAF injection but its CH50 value was not statistically significant.

\section{DISCUSSION}

Research has shown that the recombinant expression of AChR is largely achieved by extraction from human muscle, which is relatively difficult to obtain. Only a small amount of AChR can be extracted from muscle and it degrades quickly once separated. AChRTE is able to react with the AChRMU mAbs, including mAbs specific to AChR of the ECD and MIR regions. It is possible to express AChRMU $\alpha$ subunit ECD protein using AChRTE recombination (Luther et al., 1989).

Literature on AChR expression in the human muscle is limited (Luther et al., 1989; 
Talib et al., 1991). Therefore, we used the AChRTE $\alpha 1$ subunit ECD fragment recombinant to express the ECD $(\alpha 1-207)$ protein. The protein is converted and expressed in prokaryotic systems, and usually exists in the form of an inclusion body. The primary structure of the protein is correct but it is folded in such a way as to have no activity, and it exists as an insoluble inclusion body. A prokaryotic system is selected to express the protein because it is easier to separate the inclusion body from various other proteins during purification, and the operation is simple and effective (Marston, 1986). The key steps in obtaining the activated protein are dissolution and renaturation of the inclusion body, and the target protein obtained in the experiment exists in the form of the inclusion body.

Generally, the protein is renatured using either the dilution or the dialysis/ultrafiltration/electrodialysis method (Bae et al., 2013; Yang et al., 2013; Noritomi et al., 2014). The dialysis method is applicable to renaturation of target protein. It ensures correct folding of the target protein and ultra-strong immunogenicity, which facilitates successful immunization of the EAMG animals. The protein stability is not good and it precipitates after repeated freezing and thawing. The protein concentration also decreases. This necessitates an increased injection volume during immunization of the animals, thereby causing difficulties in the animal experiment. During the experiment, various methods of concentration are used and protein characteristics are enhanced; glycerin is used to concentrate the protein and improve its stability. Following the glycerin treatment, no protein precipitation occurs after repeated freezing and thawing. How is the effect of the protein dissolved in glycerin achieved when it is used to immunize animals? It would be useful to conduct a test to determine the absence or presence of MG symptoms and the effect on the titer of the antibodies in the blood.

The characteristics of the immune reactions of the T and B cells in the actively immunized EAMG are more consistent with the characteristics of MG onset. Active immunity is used to establish models and test the function to express DAF in the experiment. The diagnostic criteria for MG may also be used for evaluation of the EAMG models. Detection of $\mathrm{AchR} A b$ in serum is generally an important diagnostic criterion for AchR Ab. It can reflect the severity of MG symptoms to a certain degree but its titer level is not parallel to the MG symptoms. In this experiment, only the rats in the $400-\mu$ g experimental group had mild myasthenia symptoms but the antibody level was improved significantly in that group based on antibody titer detection. New drugs or immunosuppressors can be injected into the EAMG models to evaluate their curative effect and test the result. The models can also be used to observe the role of the drugs in protecting AchR and inhibiting the complement system.

$\mathrm{CH} 50$ is one of the most sensitive indices for reflecting the complement activation degree. In this experiment, it was found that there were no statistically significant changes in the CH50 value before and after the injection of rDAF, which does not inhibit the complement. The serum was diluted 100 times in the in vitro experiment and the complement concentration decreased correspondingly. rDAF could inhibit activation of the complement system. However, the complement could not be diluted to a concentration that enabled the rDAF to exert its role in the in vivo experiment. Thus, the complement inhibition activity is not necessarily able to exhibit any advantages, even when the DAF is fused with the single-chain antibody to reduce its metabolism.

DAF is anchored onto the cytomembrane surface by glycosylphosphatidylinositol, and its biological activity is only limited to its host's cells. In terms of the clinical application of DAF, it should be anchored to the surface of the target cells like its natural protein, thereby enabling it to exert its protective role to best effect. In the research by White et al. (2004), a cysteine was added to C terminal of DAFSCR1-4 using genetic engineering technology. It was 
anchored onto the cytomembrane surface by coupling the cysteine and cysteine residues of myristoyl polypeptide with a disulfide bond, and the DAF was anchored such that its protective capability was strengthened significantly. Some researchers have used a single-chain antibody to anchor the regulatory factor DAF (Zhang et al., 2001) or CD59 (Zhang et al., 1999) to the specific proteins on the cytomembrane surface in a non-covalent manner. This is inevitably the direction for future development of the regulatory factors of the soluble complement.

In conclusion, it is easy to induce the EAMG model by obtaining the AChRTE $\alpha 1$ subunit ECD protein using the substitution method. In this experiment, we also established that rDAF plays a role in inhibiting the complement in vitro but not in vivo.

\section{Conflicts of interest}

The authors declare no conflict of interest.

\section{REFERENCES}

Amsbaugh DF, Hansen CT, Prescott B, Stashak PW, et al. (1972). Genetic control of the antibody response to type 3 pneumococcal polysaccharide in mice. I. Evidence that an X-linked gene plays a decisive role in determining responsiveness. J. Exp. Med. 136: 931-49.

Bae SW, Ahn K, Koo YM and Ha SH (2013). Refolding of laccase in dilution additive mode with copper-based ionic liquid. Appl. Biochem. Biotechnol. 171: 1289-1298.

Conti-Fine BM, Milani M and Kaminski HJ (2006). Myasthenia gravis: past present, and future. J. Clin. Invest. 116: 2843-2854.

Gilhus NE, Owe JF, Hoff JM, Romi F, et al. (2011). Myasthenia gravis: a review of available treatment approaches. Autoimmune Diseases. 2011: 847393.

Gunewardene N, Dottori M and Nayagam BA (2012). The convergence of cochlear implantation with induced pluripotent stem cell therapy. Stem Cell Rev. 8: 741-754.

Hunt LT (2014). What are the neural origins of choice variability? Trends. Cogn. Sci. 18: 222-224.

Kalel A, Novozhilova E, Englund-Johansson U, Stupp SI, et al. (2014). Exogenous BDNF and chondroitinase ABC consisted biomimetic microenvironment regulates survival, migration and differentiation of human neural progenitor cells transplanted into a rat auditory nerve. Neur. Med. 5: 86-100.

Li BW, Rush AC, Mitreva M, Yin Y, et al. (2009). Transcriptomes and pathways associated with infectivity, survival and immunogenicity in Brugia malayi L3. BMC Genomics 10: 267.

Lin F, Kaminski HJ, Conti-Fine BM, Wang W, et al. (2002). Markedly enhanced susceptibility to experimental autoimmune myasthenia gravis in the absence of decay-accelerating factor protection. J. Clin. Invest. 110: 1269-1274.

Luther MA, Schoepfer R, Whiting P, Casey B, et al. (1989). A muscle acetylcholine receptor is expressed in the human cerebellar medulloblastoma cell line TE671. J. Neurosci. 9: 1082-1096.

Marston FA (1986). The purification of eukaryotic polypeptides synthesized in Escherichia coli. Biochem. J. 240: 1-12.

Nastuk WL, Strauss AJ and Osserman KE (1959). Search for a neuromuscular blocking agent in the blood of patients with myasthenia gravis. Am. J. Med. 26: 394-409.

Noritomi H, Kato Y and Kato S (2014). Efficient protein refolding using surfactants at high final protein concentration. $J$. Surface Engineered Materials and Advanced Technology 4: 9-13.

Pasutharnchat N, Wacharapluesadee S and Hemachudha T (2012). Clinical manifestations of acetylcholine receptor antibody positive and negative myasthenia gravis. J. Med. Assoc. Thai. 95: 313-319.

Patrick J and Lindstrom J (1973). Autoimmune response to acetylcholine receptor. Science 180: 871-872.

Peterson GL (1983). Determination of total protein. Methods Enzymol. 91: 95-119.

Sathasivam S (2008). Steroids and immunosuppressant drugs in myasthenia gravis. Nat. Clin. Pract. Neurol. 4: 317-327.

Talib S, Leiby KR, Wright K and Okarma TB (1991). Cloning and expression in Escherichia coli of a synthetic gene encoding the extracellular domain of the human muscle acetylcholine receptor alpha-subunit. Gene 98: 289-293.

Wei L, Chu M, Zhang Q, Wang Y, et al. (2014). Interleukin-12 gene adjuvant increases the immunogenicity of virus-like particles of human papillomavirus type 16 regional variant strain. Braz. J. Infect. Dis. 18: 65-70.

White J, Lukacik P, Esser D, Steward M, et al. (2004). Biological activity, membrane-targeting modification, and crystallization of soluble human decay accelerating factor expressed in E. coli. Protein Sci. 13: 2406-2415. 
Willcox N, Leite MI, Kadota Y, Jones M, et al. (2008). Autoimmunizing mechanisms in thymoma and thymus. Ann. N. Y. Acad. Sci. 1132: 163-173.

Yang CY, Li M, Dong XY and Sun Y (2013). A double-modification strategy for enhancing charge density of mono-sized beads for facilitated refolding of like-charged protein. J. Chromatogr. A. 1299: 85-93.

Zhang H, Lu S, Morrison SL and Tomlinson S (2001). Targeting of functional antibody-decay-accelerating factor fusion proteins to a cell surface. J. Biol. Chem. 276: 27290-27295.

Zhang HF, Yu J, Bajwa E, Morrison SL, et al. (1999). Targeting of functional antibody-CD59 fusion proteins to a cell surface. J. Clin. Invest. 103: 55-61. 